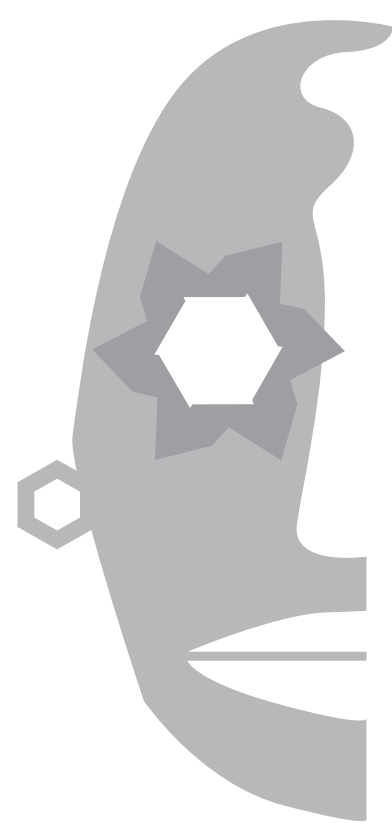

Mauricio Espinoza

The Ohio State University

\section{Círculos viciosos: migración y violencia en la narrativa y el cine trans-centroamericanos}

\section{Resumen}

La migración, tanto intra-ístmica como trans-ístmica, ha marcado la vida de millones de centroamericanos a finales del siglo XX y principios del siglo XXI. Este ensayo analiza dos obras representativas del reciente subgénero narrativo de la migración centroamericana: la novela The Tattooed Soldier (El soldado tatuado, 1998), de Héctor Tobar, y el largometraje El camino (2007), dirigido por Ishtar Yasin. En él se arguye que ambos textos abordan la migración de ciudadanos centroamericanos mediante una estrategia narrativa identificada como "violencia circular desterritorializada". En este sentido, la violencia inicial (nacional, territorializada) migra junto a los protagonistas hacia los países receptores, transformándose en un fenómeno transnacional y desterritorializado. Debido al carácter transnacional y circular de esta violencia, los personajes no logran escapar de ella y más bien terminan en peores circunstancias después de migrar a la supuesta "tierra prometida". Por medio de esta estrategia narrativa, The Tattooed Soldier y El camino critican la forma en que los centroamericanos más vulnerables han sido víctimas de una violencia estructural e institucionalizada que se extiende más allá del territorio nacional y cuyo origen y causa común es la desigualdad socioeconómica y la precariedad que marcan a estos individuos antes y después de convertirse en migrantes.

Palabras clave: migración; violencia; Centroamérica; desterritorialidad; transnacional.

\footnotetext{
Abstract

Migration both within and outside the Central American isthmus has marked the lives of millions of Central Americans in the late twentieth and early twenty-first centuries. This essay analyzes two works representative of the recent narrative subgenre centered on Central American
} 
migration: the novel The Tattooed Soldier (1998) by Hector Tobar and the feature film El camino (2007) directed by Ishtar Yasin. It argues that both texts approach the migration of Central American citizens through a narrative strategy identified as "deterritorialized circular violence" in which the initial violence (national, territorialized) migrates with the protagonists of both stories to their recipient countries, transforming along the way into a transnational, deterritorialized phenomenon. Due to the transnational, circular nature of this violence, the characters are not able to escape it and rather end up in worse circumstances after their voyage to their supposed "promised land." Through this narrative strategy, The Tattooed Soldier and El camino make powerful commentaries on the way vulnerable Central Americans have become victims of structural, institutionalized violence that extends beyond the national territory - and whose origin and common cause is the socioeconomic inequality and precariousness that impact these individuals before and after becoming migrants.

Keywords: Migration; violence; Central America; desterritoriality; transnational.

La migración, tanto intra-ístmica como hacia otros países, especialmente Estados Unidos, ha marcado las vidas de millones de centroamericanos a finales del siglo XX y principios del siglo XXI. Forzados al exilio a raíz de las dictaduras o conflictos armados que desangraron a la región, o empujados a salir de sus países por presiones económicas extremas o inseguridad ciudadana, ${ }^{1}$ estos migrantes han establecido comunidades centroamericanas transnacionales que continúan redefiniendo y problematizando el concepto tradicional de la "nación" como territorio geográfico inamovible. Las experiencias de estos individuos, y el impacto que han causado en sus países de origen y en los países receptores, han generado en los últimos años varias obras literarias y cinematográficas en torno al tema de la migración, impulsado por escritores y directores radicados en Centroamérica, así como otros de ascendencia centroamericana pero nacidos en los países hacia donde sus padres emigraron.

En este ensayo se analizan dos obras representativas de la narrativa y cine de migración centroamericana: la novelaThe Tattooed Soldier (El soldado tatuado, 1998), del periodista y autor Héctor Tobar (1963), nacido en California de padres guatemaltecos, y el largometraje El camino (2007), de la actriz y cineasta costarricense Ishtar Yasin (1968). Estas obras tienen dos características en común: el carácter transnacional de sus mundos narrativos y la presencia ubicua de la violencia como la fuerza principal que moldea las vidas de sus protagonistas y los espacios en que se desenvuelven. En El soldado tatuado, un joven guatemalteco de las clases populares, Antonio Bernal, ha huido de la guerra civil de su país hacia Los Ángeles, California, luego de que su esposa y su hijo fueran asesinados por miembros de un escuadrón de la muerte. En lugar de oportunidades para iniciar una nueva vida, Antonio termina viviendo en la calle y en la pobreza junto

1 Un análisis detallado sobre el fenómeno de la migración centroamericano es ofrecido por María Cristina García en Seeking Refuge: Central American Migration to Mexico, the United States, and Canada (Berkeley, CA: University of California Press, 2006); y por Carlos Sandoval García en No más muros: Exclusión y migración forzada en Centroamérica (San José, CR: Editorial de la Universidad de Costa Rica, 2015). 
a muchos otros inmigrantes latinoamericanos sin documentos y sin esperanzas. Además, la violencia que experimentó en Guatemala lo persigue, ya que un día descubre en la misma ciudad a Guillermo Longoria, uno de los soldados que mató a su familia, y de quien decide vengarse. En El camino, dos niños nicaragüenses que viven en la extrema pobreza, Saslaya y Darío, abandonan a su abuelo incestuoso en busca de su madre, quien años atrás había emigrado a Costa Rica en busca de una mejor vida. Aunque Saslaya llega finalmente a su destino, no logra encontrar a su madre y termina en un prostíbulo, atrapada en la misma vida de pobreza y violencia sexual de la cual trató de escapar.

El presente análisis propone que las dos obras abordan la migración de ciudadanos centroamericanos a través de una estrategia narrativa que identifico como "violencia circular desterritorializada", utilizando el concepto de desterritorialización de Néstor García Canclini como punto de partida, y luego adaptándolo a las situaciones particulares de estas narrativas. En este sentido, la violencia inicial (nacional, territorializada) migra junto con los protagonistas hacia los países receptores, transformándose en un fenómeno transnacional y desterritorializado. Debido al carácter transnacional y circular de esta violencia, los personajes no logran escapar de ella y, en cierta, forma terminan en peores circunstancias después de migrar. Por medio de esta estrategia narrativa, ambas obras problematizan la forma en que los centroamericanos más vulnerables han sido víctimas de una violencia estructural e institucionalizada que se extiende más allá del territorio nacional y cuyo origen y causa común es la desigualdad socioeconómica que marca a estos individuos y que arrastran luego de convertirse en migrantes.

En Culturas hibridas: Estrategias para entrar y salir de la modernidad (1989), García Canclini se refiere a la desterritorialización como un proceso que implica "la pérdida de la relación "natural"" de aspectos de la cultura de un país con sus "territorios geográficos y sociales” (Canclini: 1989, p. 288). Según García Canclini, la relocalización -o más bien, "deslocalización" - de las culturas nacionales contemporáneas está íntimamente ligada a la transnacionalización de los mercados simbólicos en una época de auge globalizador, así como a la creciente migración de personas de todos los estratos socioeconómicos, junto con sus prácticas y producciones culturales (pp. 288-290). Este proceso de desterritorialización, apunta García Canclini, es capaz de generar nuevas formas de producción cultural híbridas y muy dinámicas, tal y como se evidencia en la zona fronteriza entre México y Estados Unidos y en la emergente producción artística latino-estadounidense. Al mismo tiempo, la deslocalización de millones de latinoamericanos en Estados Unidos y otras regiones del mundo tiende a mostrar "su rostro doloroso", que incluye "el subempleo y desarraigo de campesinos e indígenas que debieron salir de sus tierras para sobrevivir” (pp. 290-291), sin mencionar el impacto de 
estos movimientos en las comunidades de los migrantes y los riesgos asociados, tanto con la travesía migratoria como con la estadía, por lo general indocumentada o "ilegal", de estos individuos en los países receptores. El "rostro doloroso" de la desterritorialización -representado por actos de violencia que marcan el antes, el durante, $\mathrm{y}$ el después de la migración de individuos centroamericanos a finales del siglo XX y principios del siglo XXI- es retratado en toda su crueldad tanto por El soldado tatuado como por El camino, cuyos personajes navegan a la deriva en sendas rutas de violencia, desarraigo, y desesperanza. Al mismo tiempo, la novela y el filme también se articulan como formas de producción cultural transnacionales, que obligan a reformularse el significado y la existencia misma de literatura y cine puramente "nacionales" en el nuevo panorama cultural y artístico.

El soldado tatuado -finalista del premio PEN Center/USA West Award for Ficiton-narra la historia de guatemaltecos impactados por la guerra y sus espectros, entre principios de la década de los ochenta y 1992, tanto en Guatemala como en la ciudad estadounidense de Los Ángeles. El protagonista, Antonio, es un estudiante de literatura que se involucró con grupos de izquierda en la Universidad de San Marcos. Antonio huyó hacia Estados Unidos luego de que su esposa y también militante estudiantil, Elena, y el hijo de dos años de ambos, fueron asesinados en el pueblo de San Cristóbal Acatapán, donde se habían refugiado para tratar de evadir al ejército guatemalteco que ya había matado o desaparecido a varios de sus compañeros. A través de estos personajes y sus circunstancias extremas, Tobar retrata el terror de la guerra civil guatemalteca, que duró 36 años y dejó más de 200.000 muertos (Miller, 2011, p. 1). Antes de abandonar su país, Antonio vio en el parque del pueblo a uno de los asesinos de su familia, conocido como Longoria, quien portaba el tatuaje de un jaguar en su antebrazo, pero en ese momento no tuvo el valor de confrontarlo. Antonio se había imaginado que Los Ángeles era un sitio glamoroso tal y como se le mostraba en películas, un lugar "where he would redeem himself, undertake a new beginning", por ejemplo, continuando sus estudios de literatura en la universidad UCLA (Tobar, 1998, p. 51). Antonio también se esperaba un lugar repleto de gringos rubios de ojos azules, pero más bien se encontró un mar de rostros oscuros y de español hablado en todos los rincones, "thousands upon thousands of Mexicanos, Guatemaltecos, and Salvadoreños, more than he ever imagined" (Tobar, 1998, p. 71). Uno de ellos resultaría ser su enemigo mortal. La "tierra prometida" también estaba repleta de violencia en los barrios pobres, homicidios, y confrontaciones entre las maras, otro producto transnacionalizado y desterritorializado entre Estados Unidos y Centroamérica. Antonio termina siendo víctima de la precaria situación económica de los inmigrantes indocumentados. Al principio de la novela, el protagonista ha sido desahuciado de su apartamento y es forzado a irse a vivir entre los indigentes y "refugiados" de la ciudad. 
Antonio y las circunstancias trágicas que envuelven su vida son excelentes ejemplos de desterritorialización y circularidad de la violencia. Cuando huyó de su país, cargó sus pocas pertenencias en una caja de cartón. Cuando es forzado a abandonar su apartamento en Los Ángeles, acarrea sus cosas en una bolsa plástica por las calles de la ciudad y "debajo del freeway" (Tobar, 1998, p. 7), donde termina conviviendo con otros desposeídos. Tobar emplea la caja y la bolsa como metáforas de la movilidad forzada, del desapego, de la imposibilidad de construir y mantener un hogar, de plantarse y establecerse en un territorio propio. Tobar también utiliza la imagen del parque para conectar las historias personales de Antonio y el soldado Longoria, así como para crear una especie de puente espacio-tiempo entre los actos de violencia perpetrados en Guatemala y en California. Cuando Antonio ve por primera vez al asesino de su familia, ambos están en un parque en San Cristóbal Acatapán, mientras Antonio espera el autobús; cuando lo reconoce por su tatuaje en Los Ángeles, Longoria está jugando ajedrez en el MacArthur Park, como es su costumbre. Inesperadamente, la imagen del parque hace que las dos realidades colisionen violentamente: "Antonio spun in the flux between decades and countries, time and space distorted. He was in a park in Guatemala, a park in Los Angeles. The present, the past, somewhere in between"(Tobar, 1998, p. 79). El acto de violencia que transformó la vida de Antonio se desterritorializa cuando Longoria migra a Los Ángeles y las vidas de ambos se cruzan de nuevo en ese parque, dando lugar a nuevas formas de violencia y convirtiéndose, efectivamente, en un círculo interminable que liga ambos países y realidades, pasado y al presente.

La construcción del antagonista, el sargento Guillermo Longoria, del Batallón Jaguar (motivo de su tatuaje), también está marcada por el inescapable círculo de la violencia y por estructuras políticas de carácter transnacional. Durante su paso por el ejército guatemalteco en la década de los ochenta, recibió entrenamiento por parte de la Escuela de las Américas en Panamá y en suelo estadounidense, hecho que involucra a Estados Unidos en el círculo de violencia desterritorializada, incluso antes de que Longoria emigrara a ese país. A pesar de haber asesinado a gran cantidad de sus compatriotas como parte de la represión gubernamental, Longoria también es representado por Tobar como una víctima más de la violencia institucionalizada, ya que no ingresó al ejército por cuenta propia sino que fue reclutado a la fuerza e ilegalmente cuando era aún menor de edad, durante una redada en un sala de cine. De hecho, cuando fue secuestrado por el ejército, el adolescente de ascendencia indígena e hijo de familia campesina se encontraba viendo la película E.T., El Extraterrestre durante un viaje a Huehuetenango, donde su madre lo había enviado a comprar jabón y con instrucciones de no distraerse. En el ejército, el niño Guillermo pasó a ser Longoria, y aprendió a hacer cosas crueles y horribles, a obedecer órdenes para sobrevivir (Tobar, 1998, p. 63). 
Después de su adoctrinamiento y transformación en un asesino inescrupuloso, Longoria dice sentirse justificado en cierta forma por sus acciones, asegurando que luchó para salvar a Guatemala del comunismo y para crear un país de guerreros y hombres honorables (Tobar, 1998, p. 200).

En Los Ángeles, donde ha dejado de ser soldado y es un inmigrante más, Longoria no logra escaparse del pasado de violencia que acarrea. Allí trabaja en una empresa que envía paquetes a Centroamérica, propiedad de un nacionalista de derecha salvadoreño. Algunos de sus clientes, que en el pasado bien pudieron haber sido sus víctimas, reconocen su mirada de soldado: "This was his practiced soldier's gaze, his cara de matón, the look that said he was one of the serious ones, the type to grin after he hit you over the head with his rifle butt. Anyone from Central America recognized this look" (Tobar, 1998, p. 25). En una ocasión, una mujer indígena vio su tatuaje y lo reconoció como uno de los "matones", gritando y rogándole que le dijera dónde estaba el cuerpo de su hijo asesinado por el ejército. Junto a exsoldados como Longoria, también emigraron a Los Ángeles muchos de los izquierdistas que aún detesta. De hecho, el sargento expresa su enojo cuando ve una demostración organizada por exiliados centroamericanos, quienes protestan contra la represión en El Salvador y Guatemala, y se pregunta cómo es posible que les permitan expresarse así en este país, y que era el colmo que él "had come three thousand miles from his country to find these people again, these Communists, up to their old tricks" (Tobar, 1998, pp. 67-68). Aunque la nueva realidad de su país adoptivo no le permite a Longoria lidiar con los izquierdistas de la forma en que lo hizo una vez en Guatemala, la tensión entre ambos bandos aún está presente, ahora importada a un nuevo escenario.

No obstante, hay una persona en Los Ángeles para quien esta violencia circular aún reclama un acto de venganza, un cadáver más, un muerto desterritorializado. Después de haber descubierto a Longoria en el MacArthur Park de Los Ángeles, Antonio se obsesiona totalmente con el deseo de vengar la muerte de sus seres queridos, pero también la de tantos otros compatriotas que perecieron a manos de este asesino, asumiendo una posición de militante justiciero: "I did not bury my wife and child, but I can stand and seek vengeance, for them and for the many, for the anonymous dead [...] Elena knew that to march with the many was to stand tall. Elena loved me because she knew I could be a brave fighter" (Tobar, 1998, p. 183).

Antonio encarna ahora el papel del depredador, siguiendo cada movimiento de Longoria, ingresando a su apartamento para obtener información sobre él y, finalmente, trazando un plan cuidadoso para acabar con su vida. Antonio va al parque a matarlo, armado con un tubo de metal, ya que no tiene suficiente dinero para comprar un arma de fuego. Cuando Antonio lo golpea, Longoria reconoce que la confrontación con este desconocido significa que "that the war had started again" 
(208). Sin embargo, cuando está a punto de ultimarlo, la policía interviene. Antonio no desiste, y logra obtener una pistola. En lo que resulta ser una coyuntura muy significativa, el día en que Antonio se prepara para buscar a Longoria otra vez y matarlo, es la fecha en que estallan los motines y saqueos causados por el resultado del juicio contra los agresores de Rodney King, en 1992 -un evento que puso en evidencia el problema estructural de la violencia estatal contra minorías étnicas en esta ciudad (Cannon, 1999, pp. 18-19). Antonio ve ese día de insurrección en que las minorías abusadas de la ciudad claman por justicia como el momento perfecto para cumplir su cometido a nombre de las víctimas de Longoria. Cuando finalmente logra acribillar al soldado tatuado, Antonio piensa: "The blood of Los Angeles might soon begin to fade. The blood of Guatemala was indelible" (Tobar, 1998, p. 304). El asesinato del asesino marca un hito importante en la atormentada historia personal de Antonio, no obstante reconoce inmediatamente que la violencia perpetrada por Longoria y tantos otros soldados nunca podrá ser saldada ni borrada.

Aunque las circunstancias de la violencia exploradas son distintas, el filme $E l$ camino - selección oficial en el prestigioso Festival de Cine de Berlín en 2008también lidia con fenómenos circulares y desterritorializados. La película cuenta la historia de dos niños nicaragüenses pobres, Saslaya y Darío, que dejan su país con la esperanza de reunirse con su madre, quien había inmigrado a Costa Rica siete años atrás en busca de trabajo y una mejor vida. A través de estos personajes, el filme explora las inequidades socioeconómicas que motivan la migración, así como la discriminación y difíciles condiciones que experimentan muchos de los más de 400.000 nicaragüenses que ahora viven en Costa Rica, cuya población es de menos de 5 millones de habitantes (Sandoval García, 2008,p. 25). La película se enfoca en el abuso sexual experimentado por Saslaya, quien apenas tiene 12 años, a manos de hombres explotadores en ambos lados de la frontera. En este sentido, El camino aborda la problemática de la violencia como un fenómeno en que las estructuras sociopolíticas asociadas con el concepto de la nación y aquellas relacionadas con asuntos de género se vuelven inseparables, razón por la cual deben analizarse en forma conjunta. Tanto la migración como el abuso sexual son formas de violencia inextricables de principio a fin en la película. Al mostrarlas de esta forma, Yasin problematiza las instituciones estatales y culturales (como el patriarcado) que contribuyen a la perpetuación de la violencia hacia los sectores más vulnerables de la población. El Camino se enmarca en la tradición del cine hecho por mujeres latinoamericanas en las últimas décadas, el cual, de acuerdo con Liz Kotz, se caracteriza por la intersección entre asuntos de género, clase, e identidades étnicas y nacionales en una nueva realidad marcada por "exile, rupture, transnational migration and bicultural identity" (Kotz: 1997, p. 211). 
La migración forzada y el abuso sexual presentes en El camino son formas de violencia desterritorializadas ya que, aunque se originan en Nicaragua, persiguen a Saslaya a través de su largo y complicado trayecto, atrapándola una vez que llega a su destino al otro lado del fronterizo Río San Juan. Una lectura "territorial" de este filme es adecuada, ya que El Camino se estructura como un "road movie", empezando ya por su título. Sin embargo, a pesar del papel primario que la locomoción y el cambio juegan, Yasin subvierte la noción del viaje cinemático como el movimiento entre un punto $\mathrm{A}$ y un punto $\mathrm{B}$, al término del cual atestiguamos alguna hazaña heroica, una iluminada transformación, o el haber encontrado el añorado objeto del deseo. El filme se resiste a esta fórmula triunfalista y se estructura como un viaje circular vicioso: Saslaya huye de la pobreza extrema de su existencia en un enorme basurero en las afueras de Managua y el abuso sexual de su abuelo, pero termina en las fauces del "hombre del bastón" y su prostíbulo en Costa Rica. En el país del sur, que se supone sería su "tierra prometida", la niña termina siendo marginalizada y abusada, tal y como le ocurría en su patria. Además, pierde en el camino a su hermano (no sabemos a ciencia cierta si muere, pero tal destino es sugerido por el filme) y no logra encontrar a su madre y cumplir con la reunificación familiar. El viaje se convierte en un laberinto indescifrable, el añorado destino, una imposibilidad. La violencia socioeconómica y sexual no se queda atrás, en el territorio de la miseria y del abuelo incestuoso: viaja con Saslaya, la persigue y la esclaviza una vez más, pero ahora en un espacio extranjero donde la escala del abuso es aún mayor.

En El soldado tatuado, Tobar claramente se esfuerza en mostrar el lado oscuro del supuesto "sueño americano", criticando la forma en que un gran porcentaje de la población estadounidense -especialmente minorías étnicas- enfrentan la pobreza y la violencia de forma cotidiana. Yasin hace algo similar en El camino; como una estrategia para resistir el discurso oficial sobre la inmigración en Costa Rica, el filme le da voz a la experiencia de los migrantes nicaragüenses, de forma que cuestiona el precario tejido de la identidad nacional costarricense, exponiendo sus contradicciones y preguntando: “ $¿ Q$ Quién pertenece a la supuestamente inclusiva sociedad tica?" Aunque el país receptor es descrito como una tierra de oportunidades por varios de los migrantes que hablan en la película, Yasin también retrata su travesía como una experiencia peligrosa y dolorosa, a contrapelo del mito de igualdad y pacifismo costarricense. Dicha intervención discursiva subraya la áspera realidad de la migración que, aunque en potencia puede ayudar a mejorar la vida de individuos y familias, conlleva sufrimiento, desintegración familiar y un sentido general de desesperanza, una realidad que se oculta o diluye en la retórica dominante de anti-inmigración, en la cual los nicaragüenses no son vistos como víctimas sino como peligrosos invasores. El abuso sexual perpetrado contra Saslaya en suelo costarricense problematiza el mito nacional de este país, 
ya que pone en escena la violencia estructural que afrontan, no sólo los migrantes nicaragüenses sino otras poblaciones socioeconómicamente vulnerables. No obstante, Costa Rica no es la única nación criticada por Yasin en el filme; la directora opta por mostrar la miseria en que viven muchos nicaragüenses de la forma más radical posible, situando a Saslaya, Darío, y al abuelo en un ambiente literalmente en putrefacción, donde los más pobres rescatan materiales reciclables de las entrañas de una montaña de basura apenas para poder sobrevivir en condiciones extremas. Estos son los ciudadanos a quienes la nación nicaragüense les ha fallado. Cabe apuntar que el abuelo abusador también ha sido abusado y victimizado todos los días de su vida por las magras condiciones en que vive y que no ha logrado superar, de la misma forma en que el soldado Longoria fue forzado a unirse al ejército guatemalteco. En este sentido, la crítica anti-nacionalista que hace $E l$ camino también es de naturaleza transnacional, ya que señala las deficiencias estructurales y las desigualdades que afectan a poblaciones subalternas, especialmente mujeres, en ambos lados de la frontera.

Aunque la migración, así como su contexto político y socioeconómico son fundamentales en la construcción narrativa e ideológica de El camino, la película se enfoca en el tema de la violencia de género, mostrando las perversiones del sistema patriarcal dominante y su impacto, particularmente en las mujeres más vulnerables. La violencia sexual y la mercantilización del cuerpo femenino son dos consecuencias de dicho sistema, que se muestran y critican en el filme. Antonia Castañeda apunta que la violencia sexual tiene sus raíces en la sociedad patriarcal occidental y una ideología "that devalues women in relation to men while it privatizes and reifies women as the symbolic capital (property) of men" (Castañeda: 1993, 25). El tratamiento de las mujeres como propiedad masculina es evidente en la película, cuando el abuelo llama a Saslaya a su hamaca para "que lo caliente". Lo mismo le sucede a Luz, una joven que viaja con el "hombre del bastón" y es parte de su teatro de marionetas itinerante. Durante la travesía a Costa Rica, nos enteramos que Luz fue vendida a su "amo" por sus padres cuando era una niña y, al igual que Saslaya, termina en un prostíbulo en Costa Rica. La mercantilización del cuerpo femenino es mostrada de forma brillante por Yasin durante una escena en la que vemos al "hombre del bastón" controlando los movimientos de Luz como si fuese una marioneta más.

Otra metáfora utilizada en El camino para referirse sutilmente al tema del abuso sexual de menores es la mariposa Morpho, que aparece como imagen recurrente durante la película. En la choza en Nicaragua vemos una mariposa azul disecada entre las páginas de un libro en el momento en que el abuelo demanda la compañía de Saslaya. El "hombre del bastón" también usa una de estas mariposas en su espectáculo de marionetas, mientras Luz aparece con un vestido azul bailando como 
si estuviera en un trance. El hombre relata la historia de la mariposa, diciendo: "Una mariposa crucificada. Crucificada en su nido un día. No se percató de su dignidad. No sabía. No defendió su honor. Un clavo se incrustó en su ala. Ecos de silencio resonaron. Otros clavos continuaron el camino del mal. Un día se descubrirá el crimen. La mariposa muere". Finalmente, cuando Saslaya es llevada por Luz al prostíbulo, donde la vemos por última vez, la cámara nos muestra varias mariposas Morpho clavadas con alfileres en una pared. "Ya está clavada", dice el "hombre del bastón" en referencia a Saslaya; es una frase que conlleva connotaciones de violación sexual y de muerte al mismo tiempo. La metáfora de la mariposa azul representa la naturaleza circular y desterritorializada de la violencia sexual perpetrada contra Saslaya, quien inicia y termina el filme como un objeto de colección, disecado y atrapado, sin posibilidad de volar y escapar. La infancia de Saslaya no puede ser salvada, y pasa del abuso privado del abuelo en Nicaragua al abuso público y comercial del prostíbulo en Costa Rica. El abuso y la violencia transcienden los territorios y fronteras nacionales en este filme, de la mano de víctimas como Saslaya y Luz, y de victimarios como el "hombre del bastón".

Como fue señalado al inicio, tanto Tobar como Yasin dejan muy claro en sus narrativas que la violencia es un círculo vicioso y una problemática transnacional cuyas raíces se encuentran arraigadas en estructuras de poder que atentan contra los grupos más vulnerables de la población centroamericana. Al presentar la realidad de la migración y del abuso sexual de menores como un problema derivado de la marginalización y violencia contra las mujeres que viven en la pobreza extrema, El camino logra problematizar y desestabilizar nociones tradicionales de nación y género que contribuyen con esa violencia y marginalización. En la realidad del filme, no hay espacio para triunfalismos; por ejemplo, Luz tiene una hija pequeña en Nicaragua, a quien ha dejado con sus padres para seguir al "hombre del bastón" a Costa Rica. Podemos entonces especular que, a menos que las estructuras políticas, socioeconómicas, y culturales que perpetúan la pobreza y la violencia en ambos países sean modificadas, esta niña terminará recorriendo el mismo camino que su madre y que Saslaya. Un fenómeno similar ocurre en $E l$ soldado tatuado, donde la migración hacia Estados Unidos no garantiza una mejor vida alejada de la pobreza y la violencia en Guatemala, ya que los inmigrantes (particularmente de minorías étnicas o raciales) relegados a los barrios pobres de la ciudad angelina vuelve a ser víctimas de desigualdades sociales y económicas y de violencia. Aunque la novela concluye con la muerte del antagonista y una sensación cuasi-heroica de que en cierta forma Antonio ha logrado un poco de justicia con su "acto revolucionario" (Tobar, 1998, p. 307), su venganza, al fin de cuentas, no es más que otra instancia en que la violencia y la muerte han marcado su vida de forma tan indeleble como la sangre de su familia y de sus compatriotas. 


\section{Referencias}

Cannon, L. (1999). Official Negligence: How Rodney King and the Riots Changed Los Angeles and the LAPD. Boulder, CO: Westview Press.

Castañeda, A. “(1993). Sexual Violence in the Politics and Policies of Conquest:

Amerindian Women and the Spanish Conquest of Alta California." InA. de la Torre \& B. Pesquera (Eds.), Building with Our Hands: New Directions in Chicana Studies. Berkeley, CA: University of California Press.

García Canclini, N. (1989). Culturas hibridas: Estrategias para entrar y salir de la modernidad. México, D.F.: Grijalbo.

Kotz, L. (1997). “Unofficial Stories: Documentaries by Latin American Women.” In C.

Rodríguez (Ed.), LatinLooks: Images of Latinas and Latinos in the U.S. Media. Boulder, CO: Westview Press.

Miller, T. (2011, 7 de marzo). "Timeline: Guatemala's Brutal Civil War". Public Broadcasting Service. Recuperado de http://www.pbs.org/newshour/ updates/latin_america-jan-june11-timeline_03-07/.

Sandoval García, C. (Ed.). (2008).El mito roto: Inmigración y emigración en Costa Rica. San José, CR: Editorial de la Universidad de Costa Rica.

Tobar, H. (1998).The Tattooed Soldier. New York, NY: Penguin Books.

Yasin, I. (Directora). (2007). El Camino [DVD]. Dir. Ishtar Yasin. San José, CR: Producciones Astarté. 